\title{
Os desafios para a implementação da Lei 10.639/03: uma análise a partir de outros olhares epistêmicos
}

\author{
Fernando Santos de Jesus*
}

\begin{abstract}
Resumo
Este artigo disserta sobre a necessidade de implementação da Lei 10.639/03 nas universidades brasileiras, a partir da discussão acerca das possibilidades de encaminhar formações mais direcionadas para o lido com as diferenças inscritas nessa sociedade, uma vez que os profissionais que saem da universidade lidarão com pessoas em suas respectivas profissões. A análise é feita sob a luz de teorias filosóficas e sociológicas, que dissertam sobre o fenômeno do racismo no Brasil. Desse modo, são utilizados autores como Carlos Moore e Kabengele Munanga para encaminhar a discussão. O percurso analítico parte do pressuposto de que os cursos de licenciaturas e bacharelados das universidades brasileiras não preparam suficientemente bem os profissionais para as relações étnico-raciais no mercado de trabalho - desde as escolas, universidades, ou prestações de serviços e indústrias, acarretando perpetuação de estereótipos e preconceito racial. A importância dessa discussão diz respeito ao imaginário social brasileiro e suas imagens pejorativas em relação aos negros, pois as relações interpessoais em ambientes de trabalho e escolares podem ser transformadas a partir de conhecimentos específicos nas formações de profissionais que dialoguem melhor nos ambientes profissionais e educacionais. Palavras-Chave: Negros; Lei 10.639/03; Preconceito Racial; Estereótipos.
\end{abstract}

\section{Challenges to the implementation of the Law 10.639 / 03 : an analysis from other epistemic views}

\begin{abstract}
This study talks about the need for implementation of Law 10.639 / 03 in Brazilian universities taking into account the discussion about the possibilities to bring more targeted training to deal with the differences listed in this society, as professionals who leave university will deal with people in their respective professions. The analysis is done in the light of philosophical and sociological theories that lecture on racism phenomenon in Brazil. Thus, such authors are used as Carlos Moore and Kabengele Munanga to forward the discussion .The conceptual path assumes that the undergraduate courses and bachelor of Brazilian universities do not prepare well enough professionals for ethnic-racial relations in the labor market - from schools, universities, or services and industries, resulting in perpetuation of stereotypes and racial prejudice. The importance of this discussion concerns the Brazilian social imaginary and its pejorative images over black because interpersonal relationships in the workplace and school can be transformed from expertise in the training of professionals that communicate best in professional and educational settings.
\end{abstract}

Keywords: Black; Law 10.639 / 03; Racial prejudice; Stereotypes.

\section{Introdução}

O estudo em relações raciais no Brasil não é, de maneira alguma, tema novo entre as diversas linhas de pesquisa nas ciências humanas das universidades que mais produzem conhecimento. Nesse sentido, não inauguro nenhuma reflexão acerca da temática; somente aponto algumas assertivas sobre o assunto, que talvez possam instigar pesquisadores mais jovens a se debruçar nesse campo fértil de pesquisa.

As produções mais acessíveis sobre conhecimento filosófico ou sociológico, os chamados clássicos (caso de Platão, Aristóteles, Kant, Voltaire, Max Weber, Karl Marx e etc.), têm sido confrontadas com leituras mais atuais, sendo, por alguns pesquisadores, problematizadas como

\footnotetext{
*Endereço eletrônico: fernandosenzala@hotmail.com
}

pensamentos que poderiam ser revistos. Reiterando, existem muitas críticas tecidas para as obras consideradas clássicas para a fundação do pensamento social brasileiro. Autores como Guerreiro Ramos (1957), Gislene Aparecida dos Santos (2005) e Kabengele Munanga (2004), afirmam que obras como "Casa Grande e Senzala", de Gilberto Freyre, ou "Raízes do Brasil", de Sérgio Buarque de Holanda, alimentam um imaginário social que não reflete de maneira positiva a figura do negro e do indígena na formação dessa sociedade.

Desse modo, existem muitas vertentes do pensamento social brasileiro que têm erigido algumas dessas "obras clássicas" como a excelência do pensar, fixando-as como cânone, ou seja, obras fundamentais para que o pesquisador compreenda o 
processo de produção de usos e "sentidos" dos aportes culturais de diversas matrizes que compõem o que chamam de "Povo Brasileiro". Geralmente são obras legitimadas por grupos acadêmicos que não trabalham sob a perspectiva da malha conceitual que discute as relações raciais no Brasil.

Ambas as maneiras de compreender a pesquisa em educação, e que transbordam para as relações raciais, de certo modo, se tangenciam, pois não podemos compreender uma deslocada da outra, uma vez que a academia elegeu algumas obras como clássicas e as massificou como indispensáveis, fixando um pensamento específico de uma época que se estende até os dias de hoje no imaginário social. Entretanto, essas obras têm sido refutadas na medida em que outras correntes de pensamento, com a entrada de novos profissionais, os quais muitos já militavam no movimento social negro antes de serem docentes, discordam das proposições e ganham força dentro do cenário acadêmico.

No ano de 2003, o governo brasileiro atende a uma das lutas históricas do movimento negro sancionando, a Lei 10.639/03, que obriga as instituições de ensino em adotar o ensino de História e Cultura Negra Africana e Afro-Brasileira, valorizando os conteúdos dessas matrizes a fim de reorganizar o aporte teórico no qual nossa população constrói suas bases intelectuais. Se os intelectuais brasileiros entenderem a proposta da lei e, de boa vontade, iniciarem um processo de revisão dos conteúdos curriculares, a comunidade acadêmica poderá iniciar um processo de abalo dos alicerces viciados da academia brasileira, pois há grandes possibilidades de se criar deslocamentos que questionem a repetição incessante de teorias importadas que não contam a história do nosso povo e que, ao contrário do que pensa a intelectualidade, desqualifica os brasileiros enquanto capazes de produzir um pensamento genuíno (RAMOS, 1957).

Ressalto que essa postura anula o devir dos povos indígenas e negros, retirando a potência de seus pensamentos a partir do momento em que os seus saberes são desconsiderados e esses sujeitos são compelidos à condição de meros repetidores da visão eurocêntrica de mundo. Essa assertiva é de fundamental importância para que possamos pensar a pobreza conceitual na qual estamos acometidos, pois uma única visão de mundo impossibilita que tenhamos mais elementos como linhas de fuga.

Portanto, creio que seja de suma importância entender em que contexto as obras que se estabeleceram como clássicas na academia brasileira foram escritas e por que a elite intelectual brasileira as massificou. Importante também pensar que em todos os contextos havia contrapontos e eles não se tornaram tão acessíveis quanto às obras erigidas à condição de clássicos. A efetiva implementação da Lei $10.639 / 03$ pode ser o passo inicial para repensar a nossa história e conduzir o pensamento social brasileiro a uma nova esfera. Convido os leitores desse ensaio a fazer o exercício da reflexão acerca dessa proposição, julgando esse processo como indispensável para uma inserção satisfatória no campo da pesquisa em relações raciais no Brasil.

\section{As Obras Clássicas e seus Contrapontos: A Elite Intelectual, os Intelectuais Marginais e a Lei $10.639 / 03$}

A questão racial sempre foi pensada no processo de construção do Brasil. Carlos Moore (2009) afirma que o processo de colonização dos países latino-americanos foi condicionado a partir do modelo escravocrata baseado na questão racial, pois foi quando se inaugurou um novo modelo de escravização, pavimentado pelo racismo, e desse modo se tornou possível criar as condições básicas de exploração material de novos territórios fora do continente europeu.

O projeto europeu de conquista de novos territórios que fornecessem recursos materiais para melhores condições de vida dentro do próprio continente, o europeu, tinha que contar com um grande contingente de mão de obra para realizar trabalhos pesados e se deslocar rumo aos perigos do desconhecido. Sendo assim, seria preciso criar justificativas plausíveis para convencer o povo europeu sobre a legitimidade de submeter, não somente à força, outros povos à escravização para que houvesse progresso no seio do continente europeu.

Nesse sentido, diversas teorias sobre a inferioridade de povos encontrados em outros continentes como as Américas e o continente Africano permeavam as produções de grandes pensadores europeus da época. Contudo, segundo Moore (2009), essas teorias não surgiram do nada, pois é possível as compreender como legado histórico, antropológico e filosófico de tempos bastante remotos, mas que se tonificaram na antiguidade grega.

Para o autor (2009), o legado de racismo dos povos antigos remonta ao período final do Paleolítico, quando duas grandes porções 
populacionais habitavam regiões de climas distintos que viabilizavam diferentes fontes de recursos naturais, influenciando no modo de ser e agir de cada uma delas. Segundo ele, a porção meridional do continente Africano, de povos melanodérmicos (negros), gozava de mais recursos naturais devido ao clima mais ameno, propício à agricultura e coletivização nos meios de produção, o que levava à inequívoca conclusão de que se pautavam no estilo de vida sedentário e matriarcal.

Em contrapartida, a porção setentrional era habitada por populações leucodérmicas (Brancos) que dispunham de menos recursos naturais, condicionados ao clima rude, impróprio para o cultivo. A caça se tornara a alternativa mais viável, além disso, as vestes precisariam ser abundantes e o local de moradia deveria ser fechado para que o clima rude não pusesse suas vidas em risco. Competitividade e práticas militares são típicas dos povos que descendem dessa forma de organização social devido a instabilidades comportamentais propiciadas por ambientes pouco generosos ${ }^{1}$.

Diante dessas informações é possível direcionar nosso pensamento para as necessidades de expansões territoriais empreendidas de povos que descenderam dos leucodérmicos setentrionais, pois ao se desenvolverem em sociedades expansionistas e preparadas militarmente, não é de se espantar a capacidade que possuíam em intentos maiores para que suas condições de vida se tornassem melhores dentro e fora do próprio território.

Por esse motivo, as teorias acerca da presumida inferioridade de povos não europeus foram bem aceitas dentro do seio das sociedades europeias nos séculos seguintes, tornando legítimas as diversas investidas militares que submeteram à força milhares de pessoas para trabalhar compulsoriamente em prol do desenvolvimento tecnocientífico de um continente, sob a égide do discurso de desenvolvimento da humanidade.

Nesse sentido, o recrudescimento de teorias nas ciências humanas de nossa sociedade ainda está visceralmente ligado às teorias importadas, teorias essas que se forjaram no cerne da autodeterminação valorativa enquanto padrões universais de beleza estética, de regras morais aceitáveis e de racionalidade. Essas determinações atingiram os povos colonizados pela massificação desses valores através da retirada do cuidado de si e do epistemicídio ${ }^{2}$.

Quando se estabeleceram em terras brasileiras, as elites internacionais trouxeram consigo o legado histórico de teorias construídas através de instabilidades políticas e competitividade, isso influenciou significativamente o modo de vida que deveria ser impresso no novo território que habitariam, ou seja, seria preciso impregnar no "novo mundo" as normas de valores europeus em face de uma suposta barbárie encontrada nos nativos e nos escravizados trazidos do misterioso e exótico continente africano.

Os movimentos abolicionistas, inclusive, não saíam dessa lógica perversa; Gislene Aparecida dos Santos (2005) afirma que os mesmos estavam pautados em alguns resquícios de teorias do século XVIII, pois ainda questionavam sobre o processo de construção de um povo a partir de "melhoramentos da raça humana", é o caso de teorias como a eugenia. A autora também afirma que todo esse processo não deve ser confundido como uma bondade natural de seres humanos que se compadeciam pelo sofrimento de outros iguais, humanos, mas sim de um movimento que visava à entrada do Brasil em uma nova tendência organizativa do mundo capitalista, precisando modernizar os modos de produção e competir enquanto nação no cenário internacional.

A partir de então se torna imprescindível acentuar que a elite intelectual brasileira esteve sempre preocupada em explicar a realidade local através da importação de modelos estrangeiros de teorias que pensavam a solução dos problemas pontuais em outros tempos e realidades específicas. Isso tornou a produção teórica empreendida no seio de grupos minoritários ${ }^{3}$ muito menos circuláveis no âmbito social geral, até mesmo porque o atrelamento da elite intelectual brasileira às tendências estrangeiras tornava possível que somente aquilo que corroborava com as ideias por eles propagadas fossem assimiladas pelas grandes massas.

Foi assim que, ao longo da história, as demandas populares e de movimentos negros foram sendo forjadas a partir de teorias exógenas para explicar a sua gênese de acontecimento. Essa ocorrência retirou a potência dessas reivindicações, sob a perspectiva de ter que se adequar a um jogo político onde prevaleceria a afiliação ao que se pensava fora dos limiares dos grupos excluídos, pois a legitimidade das reivindicações só seria possível na medição do nível de assimilação de teorias internacionais.

Ramos (1957) já advertia que o problema da sociologia brasileira era a importação de modelos estrangeiros e o desejo de aplicá-los à realidade 
prática do Brasil sem que houvesse um exame acurado sobre suas especificidades. Além disso, o contexto histórico em que foram escritas essas obras tornaria impossível suas aplicações práticas ao contexto brasileiro. Segundo ele, a psicopatologia social do homem negro brasileiro seria justamente se afiliar a padrões estéticos e normas de conduta massificadas por homens brancos, também patologizados pela doença do complexo de inferioridade e da tematização aprisionadora que empreendiam aos negros. Desse modo,

A disciplina sociológica, no Brasil e nos países de formação semelhante. Como os da América Latina, tem evoluído até agora, segundo as influências exógenas que impediam, neles, o desenvolvimento de um pensamento científico autêntico ou em estreita correspondência com as circunstâncias particulares desses países. Assim, a disciplina sociológica nesses países se constitui de glosas de atitudes, posições doutrinárias e fórmulas de salvação produzidas alhures, ou ilustra menos o esforço do sociólogo para compreender a sua sociedade, do que para informar da produção dos sociólogos estrangeiros (RAMOS, 1957 p. 19).

O sociólogo (1957) afirma que em alguns estados do Brasil onde se insere uma maioria de pessoas negras e uma minoria de brancos, pode ser mais fácil que as pessoas negras se auto identifiquem com brancos ou com alguma variação racial que busque se distanciar da raça negra, já o inverso se dá em estados onde a maioria da população é branca e a minoria é negra, sendo a maior tendência de que os negros se afirmem como negros.

Para o autor (1957), isso se deve ao fato de que o nível de manipulação conceitual e a massificação do ethos europeu em todo Brasil transformou as relações cotidianas, de modo que a desagregação entre negros afetou as localidades onde os grupos mais numerosos perdessem a autonomia de decidir os padrões estéticos e morais entre si. O contrário ocorreu nas localidades onde os negros eram minorias, pois o sentimento de pertença em grupos mais coesos tornou mais fácil a barragem de teorias importadas como normas para o grupo, que deveria seguir seus próprios preceitos. Obviamente que isso é uma possibilidade, e não se institui como regra.

De acordo com Carlos Moore (2010), um grande exemplo da desagregação dos grupos negros brasileiros veio na adoção do marxismo como solução explicativa para a situação do negro no Brasil. Para esse autor, as teorias marxistas jamais podem ser utilizadas como aliadas na luta de emancipação do povo negro e a explicação é simples: Karl Marx e Friedrich Engels eram racistas e não pensavam o proletariado europeu da mesma maneira que pensava os seres humanos negros do continente africano e da sua diáspora.

Moore (2010) afirma ainda que as correspondências que Marx trocava com seu companheiro Engels demonstravam claramente o caráter racista com que eles percebiam os africanos e seus descendentes, levando à inequívoca conclusão que eles eram racistas convictos. Marx escreveu certa vez que apoiava a invasão inglesa na Índia sob o argumento de que os indianos viviam em um estado de barbárie e deveriam receber uma educação digna (europeia) para que pudessem evoluir enquanto pessoas e sociedade.

A obra de Carlos Moore (2010) não é uma obra antimarxista, ao contrário, é a demonstração de que as obras de Karl Marx ainda carecem de ser melhor exploradas no que concerne à real intenção do autor na inscrição do seu tempo e sociedade em face de outros acontecimentos no mundo. Isso demonstra que ele sabia que o enriquecimento do continente europeu só fora possível através da escravização de negros em outros continentes, mas, talvez, não tenha se compadecido dessa situação por motivos de crenças pessoais e/ou políticas. Esse ponto de vista retira a blindagem desse autor, ou, em outras palavras, põe em xeque a "religiosidade" marxista empreendida pelos intelectuais de esquerda, instaurando uma dinâmica que contribua para que se possa pensar outros desdobramentos históricos que não constam nas bibliografias que mais circulam.

Outra reflexão importante feita por Moore (2010) diz respeito à negação de Marx e Engels em relação a outros movimentos de libertação realizados na diáspora negra e no continente africano como o caso da revolução haitiana ${ }^{4}$. Marx escrevia em um jornal estadunidense e panfletava em prol da revolução do proletário, contudo, Moore (2010) adverte que esse proletário do qual ele se compadecia era o proletário branco europeu, uma vez que não escreveu uma nota sequer que condenasse a escravização de negros africanos, bem como nenhum comentário elogioso ou de apoio sobre os levantes negros na África e nas Américas contra os opressores brancos. Como teria Marx se calado diante do mais hediondo crime contra a humanidade, a escravização? Fica a pergunta. 
Na África, na Índia e na Oceania as massas negras lutavam desesperadamente contra o invasor branco. Nas Américas, os escravos se rebelavam continuamente. Assim, Marx e Engels foram testemunhas não apenas da agressão ariana, mas também de uma resistência universal. Ora, sua postura diante desses conflitos de autodefesa e libertação nacional foi marcada pela indiferença. Esses "grandes internacionalistas revolucionários" não expressaram sequer uma vez nem mesmo sua "solidariedade moral" quando confrontados com as inúmeras insurreições negras nas Américas. De fato, calaram-se completamente diante da Revolução do Haiti de 1804, o maior evento revolucionário do século XIX (...) Marx e Engels dificilmente podem ser acusados de desconhecerem os conflitos que se desenrolavam em países distantes como a Jamaica, o Sudão, a Guiné, a África do Sul e a Índia, uma vez que ambos eram jornalistas de importantes jornais europeus e norte americanos. Eles certamente estavam bem informados sobre a luta dos negros na África do Sul sob a liderança de Cetewayo, a resistência dos negros no Sudão sob o comando de El Mahdi, a insurreição dos negros nos Estados Unidos liderados por Naty Turner e a luta dos guineanos sob a liderança de Samory Toure (MOORE, 2010 p. 82-83).

Sempre existiram obras que divergiram de pensadores como Gilberte Freyre ou Raimundo Nina Rodrigues, por exemplo, todavia não são obras que causam impacto no grande conjunto de sociedade, justamente por abalar as estruturas que mantêm vivo os privilégios sociais das classes mais abastadas e suas negociações com as classes médias. Aqueles que teorizaram em favor da descolonização do pensamento e em prol da "democratização" do acesso aos espaços de construção de conhecimento, tiveram a propagação de suas obras freadas e, ao contrário, essas obras foram marginalizadas e transformadas em literaturas de pouca ou nenhuma utilização.

A elite brasileira sempre temeu o debate sobre as relações raciais e essa ocorrência afastou dos estudos acadêmicos textos de autores como Guerreiro Ramos e Manoel Bonfim, pois estes eram grandes contestadores da sociologia positivista estrangeira adotada por sociólogos nacionais, a fim de explicar uma realidade local ${ }^{5}$. Segundo esses autores, o que levou a sociedade brasileira à ruína foi justamente a adoção de teorias estrangeiras e o esforço por entendê-las como grandes contribuições para pensar o progresso da nação.
Para muitos intelectuais brasileiros, o ensaísta Gilberto Freyre inaugurou uma sociologia brasileira em outros moldes, uma vez que passou a inserir o negro brasileiro como parte da constituição cultural do país. Conform Freyre (1949), o brasileiro é constituído de povos indígenas indolentes, negros atrasados e de elites brancas descendentes do povo mais atrasado da Europa, os portugueses. Talvez o legado dos estereótipos produzidos na obra "Casa Grande \& Senzala" acerca do negro seja o exemplo mais perceptível das relações cotidianas do nosso país, dado que dele se nutrem as tramas das telenovelas, as propagandas publicitárias, os filmes e as narrativas livrescas. Logo, fica a pergunta: como pode esse ensaísta ainda ser o referencial preferido pela elite intelectual brasileira, em tempos em que o apelo pelo politicamente correto permeia nossa sociedade?

Grande parte dos estereótipos acerca dos negros encontrados nos diversos textos e imagens circuláveis no Brasil contemporâneo foi construída desde o século XVIII e demonstra a maneira de olhar que o europeu (e as elites brasileiras numa repetição ao paradigma europeu) empreendeu para o "povo brasileiro". Mais do que isso, demonstra que foi preciso criar normas de sociabilidade e de padronização estética que rejeitassem a estética e o jeito de ser e agir africanizados ${ }^{6}$. Essas criações foram adaptadas a nossa realidade ao longo dos tempos devido aos apelos internos e externos, nos acordos espúrios entre as elites nacionais e internacionais, tomando contornos que parecem sutis, mas que na realidade são bem explícitos para os que não negam o racismo e compreendem que tal estratégia foi empreendida para que se excluíssem os negros dos espaços decisórios da sociedade, ou seja, de forma mais adocicada e menos conflitiva, amplificando o sentimento de pertença a uma nação racialmente democrática.

Embora hoje o acesso ao conhecimento seja mais dinâmico e viável - devido ao acesso às redes de contato via internet, com o crescimento dos cursos superiores, com a expansão de políticas públicas de bem estar social, expansão das escolas públicas em todos os níveis, o aumento do número de bolsas de estudos e grupos de pesquisas em mestrados e doutorados por todo o país - ainda vivemos sob o fluxo de teorias que se nutrem de intelectuais racistas de outrora, sobretudo dos séculos XVIII e XIX, e, para que seja possível compreender melhor as possibilidades de reescrever a nossa história, é preciso dar voz aos autores, 
acadêmicos ou não, marginalizados em outras épocas. Esse deve ser o desafio do novo pesquisador brasileiro nas diversas áreas de conhecimento.

Nesse sentido, penso que a Lei 10.639/03 possa ser uma ferramenta importantíssima de ruptura com os paradigmas eternos de nossa academia, pois a referida lei surge de demandas históricas nas lutas por uma educação que questione os elementos racistas persistentes em seus conteúdos disciplinares. Empreendida pelos movimentos negros que se organizaram ao longo da história do Brasil, a lei não surge da benevolência da ordem sistêmica racista, o que nos leva à inequívoca afirmação de que essa lei preconiza por conteúdos ligados à realidade prática dos negros brasileiros em comunhão com o legado africano de compreender o mundo, e isso não necessita da chancela de conteúdos europeus, transformados em clássicos, para que tenham sua importância no âmago da população.

A Lei 10.639/03 tem um caráter obrigatório em escolas públicas e particulares nos ensinos fundamentais e médios. Por esse motivo, os cursos de licenciatura buscam atender ao apelo de que seja necessário formar profissionais competentes para lidar com essa temática, tendo em vista a diversidade a ser encontrada em sala de aula. No entanto, a maioria dos cursos de licenciatura não oferece disciplinas ligadas à temática racial, na dificuldade de compreensão da proposta de efetiva aplicação da lei, que afirma ser importante e/ou fundamental para a formação docente o conhecimento de realidades diversas. Por medo ou despreparo, os departamentos dos cursos de licenciatura das universidades brasileiras ainda se omitem e resistem em trabalhar os conteúdos ligados ao continente africano e seu legado deixado na diáspora negra.

Nos cursos de bacharelado a lei também poderia ser aplicada, mesmo com um campo profissional, em princípio, distinto da docência, ou seja, os bacharéis não têm como campo de trabalho a sala de aula. No entanto, lidarão com pessoas de diferentes estratos sociais, que carregam diferentes marcas corporais, diferentes histórias de vida, diferentes percepções históricas da realidade presente e passada, pessoas de diferentes afetos. $\mathrm{O}$ profissional de qualquer área lidará com pessoas, seres humanos.

A implementação da Lei 10.639/03 em cursos de bacharelado certamente causará um grande furor, diria que muita indignação entre os setores mais conservadores que dirigem esses cursos nas grandes universidades do país e que certamente se questionarão acerca do que isso tem a ver com um tipo de trabalho mais voltado para execuções técnicas, às vezes com pouquíssimo contato com outras pessoas. Alegarão de tudo, alegarão por medo e covardia, por estarem completamente afogados na tormenta de um único modo de pensar, o modo do colonizador, pois na maioria dos casos os chefes de departamentos e centros universitários possuem uma perspectiva colonizada e jamais se debruçou em outras epistemologias, senão a dos colonizadores europeus, e isso tem uma razão de ser.

Frantz Fanon (1961) em um dos seus livros clássicos, "Os Condenados da Terra", afirma que as mentes colonizadas, nos países subdesenvolvidos, assumem o papel de "sentinelas vigilantes do legado greco-latino", guardaram no espírito os valores culturais exógenos, num processo no qual o esmagamento de outros saberes que criticam e mostram as insuficiências em relação àqueles que as elites internacionais preconizam, se tornam intoleráveis e marginais. Contudo, afirma o autor, é possível reverter esse quadro na medida em que essas mentes façam um retorno para si (olhando para os seus iguais) em um movimento doloroso de desconstrução de lugares que lhes davam a falsa sensação de bem-estar, pois quando fizerem esse movimento poderão gozar de uma plena liberdade, e tudo que lhes parecia nobre não terá mais sentido prático algum. Em outras palavras, é possível produzir um pensamento genuíno, isto é, que fale por si só, sem precisar se referendar em referenciais formalizados e/ou tornados a única via de compreensão de problemas pontuais, a partir da universalização do pensamento.

$\mathrm{Na}$ esteira desse pensamento, é sumamente importante e, possível, compreender que o empobrecimento e subdesenvolvimento da academia brasileira foram alargados pela composição política das nossas elites com as elites internacionais, as elites brancas. A recusa de implementação da Lei 10.639/03 existe em decorrência do medo da quebra do paradigma oficial, o que produz um efeito negativo para toda a sociedade (brancos e negros) na medida em que reduz as possibilidades de pensar o mundo sob várias perspectivas, prevalecendo a visão europeia. É preciso reconverter o olhar e pensar novas bases epistemológicas para que algo novo seja produzido.

bell hooks (2013) faz uma discussão muito interessante em seu livro "Ensinando a Transgredir: A Educação como Prática da Liberdade", no qual 
expõe algumas situações conflitantes vividas durante sua carreira docente. A autora busca sistematizar essas situações fazendo a interface com as teorias educacionais, recorrendo, sobretudo ao educador brasileiro Paulo Freire ${ }^{7}$. Em uma das inúmeras passagens brilhantes do livro, hooks afirma que o que potencializa a construção do conhecimento são as múltiplas vozes, ou seja, o encontro do sujeito da experiência com aportes teóricos que ajudam a sistematizar o que está no plano prático seria a viga de sustentação de processos de ensino e aprendizado satisfatórios.

Por esse motivo, é sumamente importante pensar que as ações afirmativas fazem parte do processo de justiça social, os espaços precisam ser projetados para que as múltiplas vozes sejam consideradas importantes, o lugar da produção de conhecimento ainda carece de intervenções mais duras. Estou afirmando que se a academia não consegue mais barrar sistematicamente os sujeitos marginalizados, ela criou uma hierarquia de saberes que deslegitima esses sujeitos e os seus conhecimentos, tornando-os "literatura de segunda ordem".

A Lei 10.639/03 é parte do processo que visa o equilíbrio dos conteúdos veiculados nos diversos programas de graduação e pós-graduação no país, e não somente nos ensinos fundamental e médio, pois é importante compreender que o Brasil precisa de um processo contínuo de reorganização de conteúdos programáticos a ser aplicados em todos os níveis e cursos (bacharelados e licenciaturas), uma vez que nos foi possível acessar somente um lado da história. Está na hora de recontar essa história mostrando que é possível conceber outros conhecimentos, ou seja, o conhecimento produzido pelo negro africano e diaspórico.

Os gestores dos cursos de bacharelado talvez sejam os que mais resistirão à proposta de aplicação da Lei 10.639/03, pois ainda setorizam a importância desses conteúdos nos cursos de licenciaturas. Entendo que geralmente os profissionais formados bacharéis serão aplicadores de procedimentos e normas técnicas, profissionais que estão ali para executar seus trabalhos, trabalhos que podem até ser solitários, com muito pouco ou nenhum contato com outras pessoas.

Esse pensamento minimalista não leva em consideração as coisas mais básicas da vida, isto é, tudo que se produz na sociedade é feito para atender às demandas humanas, nada do que se faz visa outro sentido senão o humano. Nesse sentido, é imprescindível que o ser humano seja compreendido em sua diversidade, caso contrário toda produção material ou prestação de serviços serão pautados num único paradigma de pessoa humana, e o paradigma vencedor é o do homem branco ocidentalizado. E é essa perspectiva única que a Lei 10.639/03 visa ressignificar, somente a reorganização desses conhecimentos pode atentar os diversos atores sociais para as minúcias do processo histórico e filosófico que levou o Brasil à adoção do paradigma europeu e à desvalorização da população negra.

Um grande exemplo do que está sendo exposto é o curso de Serviço Social, curso de bacharelado que forma para o mercado de trabalho um grande contingente de profissionais. Grande parte dos profissionais dessa área de conhecimento lida diretamente com atendimento a pessoas em condições de vulnerabilidade social, prestam atendimentos individualizado e/ou coletivo visando minimizar problemas de amplitude complexa que os põe na condição que se encontram, geralmente de extrema pobreza material e com sérios problemas psíquicos.

Dito isto, está posto que o assistente social lida majoritariamente com pessoas negras, ou seja, lida com corpos e subjetividades que ainda sofrem com o esmagamento do processo histórico de racismo no qual o mundo se estruturou. Dessa maneira, não há nada, a meu ver, mais lógico do que a necessidade de esses profissionais receberem uma formação adequada para que possam entender o processo histórico subjacente à formação do estado brasileiro em sua afiliação aos estrangeirismos que teorizou acerca dos negros africanos e da diáspora.

Os assistentes sociais recebem em sua formação diversos aportes teóricos que interpretam diversas realidades sob o prisma da teorização. No entanto, geralmente são teorias distantes da realidade brasileira, teóricos que universalizam a ideia de pobreza, sempre ligada ao capital, sem que tenham presenciado empiricamente os problemas sociais que nos assolam, e sem fazer o exame mais acurado sobre quais estratégias de combate são adotadas pelos governos locais e pelos próprios sujeitos para dirimir o problema. Novamente voltamos ao problema colocado por bell hooks (2013), é sumamente importante que haja o equilíbrio entre o sujeito que vivencia uma dada realidade e as teorias que possam sustentar a possibilidade de intervenção nessa realidade.

Acredito que na medida em que sejam adotados teóricos melhor articulados com a 
realidade empírica daquilo que se dá em âmbito local, e que façam uma leitura com o corte racial, as possibilidades de intervenção serão mais incisivas, quanto maior o contato com teorias que fazem conjecturas acerca de uma realidade vivida na prática por sujeitos que falam a partir do lugar do oprimido, mais fortificadas serão as estratégias de ação contra a pobreza. Desse modo, afirmo que a Lei $10.639 / 03$ é um importante vetor de direcionamento para adoção de autores e teorias ditas marginais que podem conduzir a um processo de reencontro do negro brasileiro consigo mesmo e do encontro do branco e do indígena brasileiro com o verdadeiro negro brasileiro, e não o idealizado pela colonialidade.

Nesse sentido, creio que não seja tentando "abrasileirar" o marxismo, ou qualquer outro tipo de teoria, que se chegará ao núcleo do problema; não será criando apêndices nas teorias produzidas distantes no tempo e no espaço que iremos resolver o nosso problema. Fanon (1961) é direto nessa questão, em seu livro "Os Condenados da Terra", ao afirmar que não será pagando tributo à Europa que os países subdesenvolvidos encontrarão o caminho para a felicidade de seus povos; a criação de uma nova sociedade não precisa do crivo das grandes literaturas, ao contrário, é preciso rejeitá-las. É preciso que o povo olhe para si mesmo e compreenda que os valores exógenos não são melhores que os saberes locais.

Portanto, camaradas, não paguemos tributos à Europa criando estados, instituições e sociedades que nela se inspirem. A Humanidade espera de nós uma coisa bem diferente dessa imitação caricatural e, no conjunto, obscena. Se desejamos transformar a África numa nova Europa, a América numa nova Europa, então confiemos ao europeu o destino de nosso país. Eles saberão fazê-lo melhor do que os mais bem dotados entre nós. Mas se queremos que a humanidade avance, se queremos levar a humanidade a um nível diferente daquele onde a Europa a expôs, então temos de inventar, temos de descobrir. Se queremos corresponder à expectativa dos europeus, não devemos devolver-lhes uma imagem, mesmo ideal, de sua sociedade e de seu pensamento, pelos quais eles experimentam de vez em quando uma imensa náusea. Pela Europa, por nós mesmos e pela humanidade, camaradas, temos de mudar de procedimento, desenvolver um pensamento novo, tentar colocar de pé um homem novo. (FANON, 1961 pp. 274-275).
Nessa mesma linha de pensamento Moore (2011) traz em seu livro "Fela, Essa Vida Puta", biografia de Fela Kuti (1938-1997), um relato no qual o músico e ativista negro nigeriano questiona o senso de grandeza que as pessoas têm de países como Rússia, Estados Unidos e China. Segundo ele, essas nações se estabeleceram a partir de um processo de destruição e usurpação por meio do qual as formas de vida tradicionais foram quase exterminadas. Por isso, aquilo que chamam de grandes feitos da história, são na verdade a face mais tenebrosa que levou o crescimento monetário dessas nações, tornando possível escamotear os horrores das guerras em nome de um falso progresso.

Portanto, reafirmo que a Lei 10.639/03 é um importante vetor para viabilizar a quebra do paradigma eurocêntrico no qual está alicerçada a academia brasileira, e, ao contrário do que muitos pensam, essa lei não pretende substituir um paradigma pelo outro, mas demonstrar que outros conhecimentos e outras formas de organização social diferente dos moldes ocidentais são possíveis e precisam ser (re)visitados, o que foi estabelecido como principal fonte de conhecimento se deu em virtude da tentativa de apagamento dessas formas de pensar.

\section{Considerações finais}

O ocidente submeteu de maneira inexorável o continente Africano e Americano a sua episteme, construída de maneira unilateral e sob a égide da violência física e moral, ou seja, a dominação europeia em relação aos continentes supracitados foi o motor principal de desenvolvimento econômico e social europeu, o que fez com que os aportes epistêmicos fossem preservados e erigidos como a gênese do pensamento filosófico universal.

A desqualificação conceitual em relação aos povos conquistados foi construída dentro do seio das sociedades europeias como parte do processo de colonização, e isso se torna evidente na medida em que é sabido que os europeus que habitavam as colônias de exploração eram pessoas marginalizadas dentro de suas sociedades, porém, ainda assim, cultivavam um sentimento de superioridade em relação aos negros e ameríndios.

Essa ocorrência fez proliferar um sentimento de ódio em relação aos negros e indígenas dentro do território nacional, comprovável na citação de Joseph Arthur Gobineau (1816 - 1882), que chamaria o Brasil de "Inferno do 
negro, o purgatório do branco e o paraíso do mulato". É patente o medo do possível enegrecimento do Brasil após o estabelecimento da elite senhorial, local, nesse país, por isso foi preciso tentar aplicar modelos conceituais importados para que se obtivesse como resultado a assunção de um povo similar na estética e na moral europeia.

O legado de toda tentativa de assassinato epistêmico, estético, moral, religioso e corporal do negro brasileiro fez emergir um ódio racial brutal que tem sido abrandado sob a égide de discursos misericordiosos na adoção de modelos estrangeiros, que desviam a atenção do racismo para questões sociais de cunho universalista. Dessa forma, a elite brasileira se fez valer da legitimidade que eles próprios criaram, fazendo do Brasil um país racista sem racistas, como dizia Florestan Fernandes (19201995), ou seja, um país preconceituoso, mas racialmente democrático.

O processo de deslegitimação dos aportes teóricos dos negros africanos e da diáspora é o intento central que a Lei 10.639/03 visa destruir, quando adverte que a adoção de novas formas de pensamento, em diversas áreas de conhecimento, pode amplificar o leque de possibilidades e linhas de fuga para um mundo melhor, e isso só será possível através do combate incansável contra esse câncer que destrói o mundo, o racismo. A implementação da Lei 10.639/03 é urgente, visto que os conhecimentos africanizados preconizam por uma humanidade respeitosa para a diversidade e totalmente desvinculada da materialidade capitalista, que faz com que sejam assassinadas diariamente milhares de pessoas pelo mundo por intolerâncias culturais potencializadas pela questão racial.

Portanto, busquei explicitar alguns pontos que dizem respeito ao processo de exclusão racial nos espaços de produção de saber, mostrando que existem literaturas que analisam o processo histórico e sociológico do Brasil e sua contextualização no cenário internacional, sugerindo que outras leituras são possíveis, fazendo emergir um vasto número de autores e publicações que podem ser utilizados como ferramentas para a compreensão de problemas específicos. Importante assinalar que muitos autores brasileiros não foram levados em consideração pela academia, que afiliada a um projeto político de tentativa de embranquecer o país, optou pela adoção de modelos epistêmicos europeus, como se fosse possível aplicá-los a nossa realidade prática (RAMOS, 1957). Ainda assim acredito que seja possível ampliar no seio da academia brasileira a produção de pensamento crítico que contribua no processo de descolonização da mentalidade acadêmica, que se transborda para o imaginário social e perdura até os dias de hoje. Desafio lançado.

\section{Notas}

1 É importante pontuar que Carlos Moore (2007) afirma que os povos leucodérmicos descendem dos melanodérmicos a partir das grandes migrações do final do período mencionado.

2 Sobre "Cuidado de Si" ver Michel Foucault (2011) - "A Hermenêutica do Sujeito", e sobre "Epistemicídio" ver Mogobe Ramose (2011) "Sobre a Legitimidade da Filosofia Africana".

3 Aqui estamos falando em termos numéricos, e não como devir minoritário no qual Félix Guattari se debruça em seu livro - "Revolução Molecular".

4 Revolução liderada por escravizados contra o sistema colonial, ocorrida no período compreendido entre 1791 a 1804 podendo ser considerada o maior levante negro contra um sistema colonial ocorrido na história, merece ser estudada com mais detalhes, fica a dica.

5 Manoel Bonfim (1868-1932) foi um médico sergipano radicado no Rio de Janeiro onde se formou em medicina e trabalhou como médico da secretaria de polícia, seguindo, posteriormente, a carreira do magistério e defendendo a escola pública. Bonfim foi um dos maiores críticos à sociologia canônica da época dele, refutando pensadores importantes como Nina Rodrigues. $\mathrm{O}$ autor era contrário à tese sobre a inferioridade do negro, sua obra mais importante é o livro "A América Latina: Males de Origem".

$6 \mathrm{O}$ termo africanizado é relativo às coisas que remetem a África, mas que não necessariamente estão no continente africano, isto é, mesmo na diáspora negra o legado ancestral africano não é apagado devido sua ressignificação e promoção positiva, os movimentos negros utilizam bastante este termo.

7 Cabe explicar que o nome da autora, negra norte americana, está em letra minúscula respeitando o posicionamento político que ela adotou quanto à utilização do seu nome nesse formato.

\section{Referências}

Horizontes, v. 35, n. 2, p. 49-58, mai./ago. 2017 
BRASIL, Lei $n^{o}$. 10.639, de 9 de Janeiro de 2003. D.O.U. de 10/01/2003.

FANON, Frantz. Os Condenados da Terra. Rio de Janeiro: Civilização Brasileira, 1961.

FREYRE, Gilberto. Casa Grande e Senzala. Livraria José Olympio, $2^{\circ}$ vol, 1949.

HOOKS, bell. Ensinando a Transgredir: A Educação como Prática Libertadora. São Paulo: Martins Fontes, 2013.

MUNANGA, Kabengele. Rediscutindo a Mestiçagem no Brasil: Identidade Nacional Versus Identidade Negra. $3^{\mathrm{a}}$ ed. Belo Horizonte: Autêntica, 2004.

MOORE, Carlos. Racismo e Sociedade: Novas Bases Epistemológicas para Entender o Racismo. Belo Horizonte: Mazza, 2009.
- O Marxismo e a questão Racial: Karl Marx e Freidrich Engels frente ao Racismo e à Escravidão. Belo Horizonte: Nandyala, 2010.

Fela, Esta Vida Puta. Belo Horizonte: Nandyala, 2011.

RAMOS, Guerreiro. Introdução Crítica à Sociologia Brasileira. Rio de Janeiro: Editorial Andes limitada, 1957.

RAMOSE, Mogobe. Sobre a Legitimidade e o Estudo da Filosofia Africana. Ensaios Filosóficos, Volume IV - Outubro/2011.

SANTOS, Gislene Aparecida dos. A Invenção do Ser Negro: Um Percurso das Idéias que Naturalizam a Inferioridade dos Negros. São Paulo: Pallas, 2005.

\section{Sobre o autor:}

Fernando Santos de Jesus é graduado em Pedagogia e Filosofia, ambas pela Universidade do Estado do Rio de Janeiro - UERJ, Especialização e Mestrado em Relações Étnico-Raciais pelo Centro Federal de Educação Tecnológica - CEFET / RJ. Atualmente e Doutorando em Educação pela Universidade Federal do Ceara - UFC, Bolsista do Conselho Nacional de Desenvolvimento Científico e Tecnológico - CNPq.

Recebido em julho de 2016.

Aprovado em maio de 2017. 